\title{
Restricted Flow Rate
}

National Cancer Institute

\section{Source}

National Cancer Institute. Restricted Flow Rate. NCI Thesaurus. Code C62849.

Problem associated with flow rate. Flow volume delivered over time is not reaching intended flow rate. 